\title{
Intraoperative Hiccups During Colorectal Surgery under total Intravenous Anesthesia (Tiva) Hiccups during Tiva
}

\author{
Mohamed E Abdul Rahman and Sohel MG Ahmed* \\ Department of Anesthesiology, Consultant Anesthetist \& Intensivist Hamad Medical Corporation, Intensive Care and
} Perioperative Medicine, Qatar

*Corresponding author: Sohel MG Ahmed, FCARCSI, Consultant Anesthetist \& Intensivist Hamad Medical Corporation, Department of Anesthesiology, Intensive Care and Perioperative Medicine, PO Box 11340 Doha, Qatar

\begin{tabular}{|c|c|}
\hline ARTICLE INFO & Abstract \\
\hline Received: 慧 November 24, 2020 & $\begin{array}{l}\text { Abbreviations: TIVA-TCI: Total Intravenous Anaesthesia Target Controlled Infusion; TCI: } \\
\text { Target Controlled Infusion }\end{array}$ \\
\hline
\end{tabular}

Citation: Mohamed E Abdul Rahman, Sohel MG Ahmed. Intraoperative Hiccups During Colorectal Surgery under total Intravenous Anesthesia (Tiva) Hiccups during Tiva. Biomed J Sci \& Tech Res 32(3)2020. BJSTR. MS.ID.005261.

\section{Introduction}

Hiccup (singultus) is a fairly common phenomenon that generally is only a nuisance but may become more troubling when prolonged [1]. Acute intraoperative hiccup is a complication that can occur during sedation or general anesthesia. The disorder can disturb the surgical field, might interfere with lung ventilation or could hamper diagnostic procedures [1], In this case report, we describe intraoperative hiccups associated with Total Intravenous Anesthesia- Target Controlled Infusion (TIVA-TCI). Written consents have been obtained from the patient and Hamad Medical Corporation Research and Ethics Committee.

\section{Case Description}

A 38-year-old male, known case of Crohn's disease for 20 years presented to our hospital with features of fibro-stenotic disease and evidence of distal ileum inter loop fistula with small abscess and minimal free pelvic collection. He was scheduled for a diagnostic laparoscopy plus/minus open laparotomy, bowel resection, double barrel ileostomy and appendectomy. Prior to induction standard monitors were applied, and all patient vitals were within normal range. General anesthesia was induced with TIVA-TCI, with propofol set at $5 \mathrm{ng} / \mathrm{ml}$ (Marsh Model) and remifentanil at $4 \mathrm{ng} / \mathrm{ml}$ (Minto Model). BIS was maintained between 40 and 60. After establishing easy Bag-Mask- Ventilation, rocuronium $40 \mathrm{mg}$ was given. The first attempt of intubation was intra-oesophageal; this was quickly noticed and corrected. A nasopharyngeal tube size 14 was inserted under direct vision. The first 30 minutes were uneventful, after which the surgeons decided to convert from diagnostic laparoscopy to an open laparotomy. Twenty minutes later, as the bowel was being resected, the surgeons started complaining of tense abdominal wall muscles and occasional contractions. An extra dose of rocuronium -20 mg- was given but in vain. The abdominal contractions were more rhythmic now and became apparent hiccups. We attempted to pull back the nasogastric tube back few centimeters believing it might be the cause, but the hiccups continued. Metoclopramide $10 \mathrm{mg}$ was given to no effect. Upon a suggestion from a senior colleague, we added sevoflurane at $1 \%$ and weaned down propofol target controlled infusion (TCI) down to $2 \mathrm{ng} / \mathrm{ml}$, maintaining the BIS between 40 
and 60 , within seconds the hiccups stopped. We were intrigued to stop the sevoflurane and put the propofol TCI up to $5 \mathrm{ng} / \mathrm{ml}$ again. The hiccups immediately restarted. We switched back to sevoflurane-based anesthesia, and the surgery ended uneventfully

\section{Discussion}

A hiccup consists of sudden contraction of the diaphragm and intercostal muscles followed immediately by laryngeal closure [1]. They commence most often during inspiration and are inhibited by elevations in PaCO2; this serves as the basis for breath holding or breathing into a paper bag as a common therapeutic intervention [1]. Hiccups may last for a day or 2, but episodes lasting longer than 48 hours are labeled as persistent, and those lasting longer than two months are regarded as intractable [1]. Persistent or intractable hiccups have been heavily reported in the medical literature. Factors including infection, trauma, tumor, and a myriad of gastrointestinal, metabolic, and psychogenic disorders have been blamed. In contrast, brief bouts of hiccups associated with anesthesia practice are more often precipitated by anesthetic medications such as methohexital, midazolam and opioids or gastric distention from swallowing blood and debris or during bagmask-ventilation [2]. A Propofol bolus is known to cause hiccups in anesthetized patients, albeit being rare [2]. Reported cases associate the development of hiccups with the rapid injection of propofol and almost occurs instantaneously. However, this seems quite unlikely in our case as it happened a good 50 minutes into the surgery, though it didn't occur post TIVA-TCI immediate induction, it did seem sensitive to the calculated infusion level. Several case series

ISSN: 2574-1241

DOI: $10.26717 /$ BJSTR.2020.32.005261

Sohel MG Ahmed. Biomed J Sci \& Tech Res

(C) This work is licensed under Creative

Submission Link: https://biomedres.us/submit-manuscript.php and case reports focused on various systemically applied drugs to treat intraoperative hiccups [2-4]. Stimulating techniques (e.g. pharyngeal stimulation), topically applied remedies (e.g. intranasal ice-cold water), and ventilation techniques (e.g. continuous positive pressure ventilation) have all been described. Lidocaine at various doses, and via different routes, has also been used with relative success [2-4].

\section{Conclusion}

We believe that multifactorial precipitants might have contributed to the development of intraoperative hiccups in the above case, e.g. intraesophageally intubation leading to gastric distension, nasogastric tube insertion, underling surgical pathology, etc. Although propofol boluses are known to cause intraoperative hiccups as well, to our knowledge, it is not recorded to occur with TIVA-TCI and with such an unusual late onset. In our case, the reduction of the calculated propofol targeted level seems to have solved the problem; we are not sure if the augmentation of the anesthesia with sevoflurane has helped in that as well or not.

\section{References}

1. Kranke P, LH Everhart, AM Morin, J Craclnell, CA Gerim, et al. (2003) Treatment of hiccup during general anaesthesia or sedation, a qualitative systemic review. European J of Anesthesiology 20(3): 239-244.

2. Boulouffe C, Vanpee D (2007) Severe hiccups and intravenous lidocaine. Acta Clin Belg 62: 123-125.

3. Cohen SP, Lubin E, Stojanovic (2001) Intravenous lidocaine in the treatment of hiccup. South Med J 94: 1124-1125.

4. Neeno TA, Rosenow EC III (1996) Intractable hiccups. Consider nebulized lidocaine. Chest 110: 1129-1130.

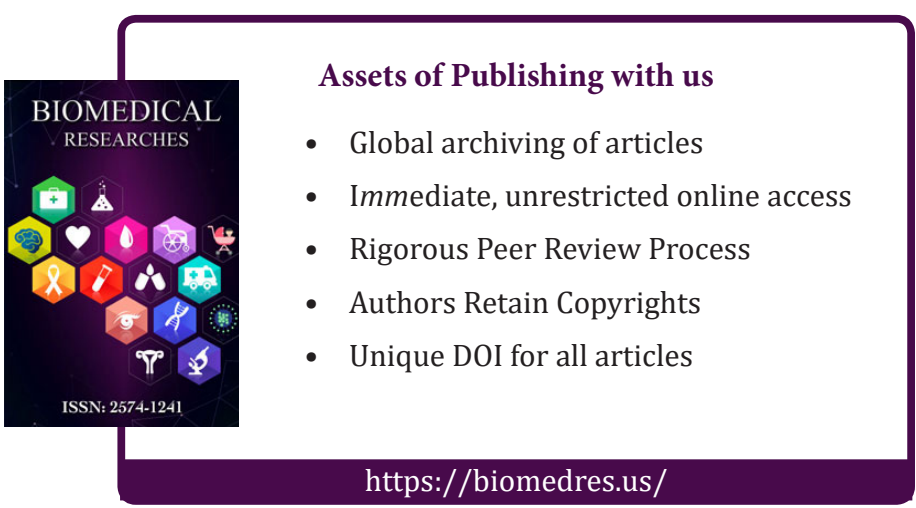

Copyright@ Sohel MG Ahmed | Biomed J Sci \& Tech Res | BJSTR. MS.ID.005261. 